\title{
Laser beam welding of a CoCrFeNiMn-type high entropy alloy produced by self-propagating high-temperature synthesis
}

\author{
Nikolai Kashaev $^{1}$, Volker Ventzke ${ }^{1}$, Nikita Stepanov ${ }^{2, *}$, Dmitry Shaysultanov ${ }^{2}$, Vladimir Sanin ${ }^{3}$, \\ Sergey Zherebtsov ${ }^{2}$ \\ ${ }^{1}$ Institute of Materials Research, Materials Mechanics, Department of Joining and Assessment, Helmholtz-Zentrum Geesthacht, Max-Planck-Str.1, 21502, Geesthacht, \\ Germany \\ ${ }^{2}$ Laboratory of Bulk Nanostructured Materials, Belgorod State University, Pobeda 85, Belgorod, 308015, Russia \\ ${ }^{3}$ Merzhanov Institute of Structural Macrokinetics and Materials Science, Russian Academy of Sciences, Academician Osipyan Str., 8, Chernogolovka, Moscow Region, \\ 142432, Russia
}

\section{A R T I C L E I N F O}

\section{Keywords:}

A. High entropy alloy

B. Phase stability

Age hardening

C. welding

D. Microstructure

\begin{abstract}
A B S T R A C T
Fiber laser beam welding of a CoCrFeNiMn-type high entropy alloy (HEA) produced by self-propagating hightemperature synthesis (SHS) was reported in this work. The SHS-fabricated alloy was characterized by both $\sim 2$ times reduced $\mathrm{Mn}$ content in comparison with that of the other principal components and the presence of impurities including $\mathrm{Al}, \mathrm{C}, \mathrm{S}$, and $\mathrm{Si}$. The as-fabricated alloy was composed of columnar fcc grains with coarse precipitates of $\mathrm{MnS}$ and fine Cr-rich $\mathrm{M}_{23} \mathrm{C}_{6}$ carbides. Successful defect-free butt joint of the alloy was obtained using a laser power of $2 \mathrm{~kW}$ and a welding speed of $5 \mathrm{~m} / \mathrm{min}$. Welding resulted in changes in texture and structure of the fcc matrix. In addition, precipitation of nanoscale B2 phase particles in the weld zone was observed. A pronounced increase in microhardness from (153 \pm 3 ) HV 0.5 (base material) to (208 \pm 6$) \mathrm{HV} 0.5$ (fusion zone) was observed. The B2 phase precipitation after welding was found to be in a reasonable agreement with the ThermoCalc predictions. Quantitative analysis demonstrated that the increase in hardness can be associated with the B2 phase precipitation. Possibilities of the development of HEAs with intrinsic hardening ability after laser processing are discussed.
\end{abstract}

\section{Introduction}

High entropy alloys (HEAs) have recently emerged as a new class of advanced metallic materials promising for various applications [1-4]. Their main feature is high complexity of chemical composition; according to the original definition, HEAs should be composed of at least 5 principal elements in close to equiatomic concentrations (5-35 at.\%) [5]. It was proposed that due to such a complex composition HEAs can possess structures and properties which cannot be attained in conventional, single-element-based alloys [1,2,6]. However, vast opportunities for novel alloys development provided by HEAs concept also present a major challenge: a special methodology is required to select promising alloys for specific applications out of numerous candidates in a timeand cost-effective way [1,7-9].

One of the promising classes of the HEAs which attract particular attention is fcc-structure $\mathrm{Co}-\mathrm{Cr}-\mathrm{Fe}-\mathrm{Ni}$-Mn system alloys. The equiatomic CoCrFeNiMn alloy was introduced by Cantor et al., in 2004 [10], almost simultaneously and independently from the first paper on HEAs [5]. The alloy was found to have a single fcc phase structure [10-13].
Later it was revealed that the alloy had unique mechanical properties; very high ductility at room temperature become even higher when the temperature decreased into the cryogenic interval. The alloy also had record-breaking fracture toughness at cryogenic temperature [14-16]. High ductility and toughness were attributed to active nano-twinning under cryogenic conditions $[14,15,17,18]$. However the alloy had relatively low yield strength $[14,16]$, which limited possible practical applications. Many efforts have been devoted to increase the strength of the CoCrFeNiMn or similar alloys by alloying and/or thermomechanical treatment [14,19-38]. It was found that among the possible strengthening mechanisms (including grain boundary and solid solution strengthening) the most potent one is precipitation hardening. For instance, the yield strength of a $(\mathrm{CoCrFeNi})_{94} \mathrm{Al}_{4} \mathrm{Ti}_{2}$ alloy after proper heat treatment (aging) increases from 503 to $1005 \mathrm{MPa}$ while maintaining sufficient ductility [36].

Although composition-structure-properties relations of the Co-CrFe-Ni-Mn system alloys are under extensive investigation at the moment, many aspects of the behaviour of these alloys have not received significant attention yet. For instance the development of effective

\footnotetext{
* Corresponding author.

E-mail addresses: stepanov@bsu.edu.ru, stepanov.nikita@icloud.com (N. Stepanov).
} 
joining technologies is important for potential application of any structural material. But not many information on welding of HEAs is available. Successful electron beam welding of the CoCrFeNiMn alloy without formation of solidification cracking was reported in by $\mathrm{Wu}$ et al. [39]. After welding, the alloy demonstrated mechanical properties very similar to those of the base material. Significant grain refinement and high hardness in the stir zone were observed in several friction stir welded fcc Co-Cr-Fe-Ni-Mn system alloys [40-42].

In contrast to the electron beam welding, laser beam welding possess a much higher flexibility and can be conducted without vacuum by using inert gas shielding. However, it is not clear, whether HEAs can be successfully laser beam welded. Recently, laser-based processes were only investigated for cladding of HEAs, where the main emphasis was given to production coatings with advanced properties [43-46], while laser welding has received rather limited attention [41]. Therefore the effect of fiber laser beam welding on the structure and hardness of the CoCrFeNiMn-type HEA was reported in the present study. The initial material was produced by self-propagating high-temperature synthesis (SHS) which recently was found to be a suitable method for HEAs production [47].

\section{Experimental methods}

\subsection{Material and laser beam welding}

The synthesis of the initial CoCrFeNiMn-type alloy was carried out with the use of thermite-type SHS powders containing oxides of the target elements ( $\mathrm{NiO}$ (99.0\% purity), $\mathrm{Cr}_{2} \mathrm{O}_{3}$ (99.2\% purity), $\mathrm{Co}_{3} \mathrm{O}_{4}$ (99.6\% purity), $\mathrm{Fe}_{2} \mathrm{O}_{3}$ (99.3\% purity), $\mathrm{MnO}_{2}$ (99.7\% purity)) and $\mathrm{Al}$ ( $98 \%$ purity) as the metal reducer. The average particle size was $50-100 \mu \mathrm{m}$ for the oxides and less than $140 \mu \mathrm{m}$ for aluminum. Combustion was carried out in graphite mold $80 \mathrm{~mm}$ in diameter. The inner surface of the graphite mold was laminated with $\mathrm{Al}$ oxide $\left(\mathrm{Al}_{2} \mathrm{O}_{3}\right)$ to ensure minimal reactive interaction between the casting-form material and the metal melt. The synthesis of the program alloy was carried out in a centrifugal SHS setup. The obtained ingot after the synthesis was $600 \pm 10 \mathrm{~g}$ in weight and had a diameter of $80 \mathrm{~mm}$ and a height of $15 \mathrm{~mm}$. The metallic (target) and oxide (slag) layers after the synthesis were easily mechanically separated into two parts: the target alloy and the oxide layer $\left(\mathrm{Al}_{2} \mathrm{O}_{3}\right)$.

The coupons for the welding (measured $15 \mathrm{~mm} \times 15 \mathrm{~mm} \times 2 \mathrm{~mm}$ ) were cut by electric discharge machining from the ingot produced by SHS and subsequently cleaned and ground. Laser beam welding (LBW) of the butt joints was performed using an $8.0 \mathrm{~kW}$ fiber laser with a fiber optic ( $300 \mu \mathrm{m}$ core diameter) and a $300 \mathrm{~mm}$ focal length. Butt joints were welded autogenously in a 3-axis Ixion CNC machine in argon atmosphere. The LBW process was performed using the following process parameters:

- The laser power of $2.0 \mathrm{~kW}$;

- The focus position of $0.0 \mathrm{~mm}$ above the specimen surface;

- The welding speed in the range between $3.0 \mathrm{~m} / \mathrm{min}$ and $6.0 \mathrm{~m} / \mathrm{min}$.

\subsection{Microstructural characterization and mechanical tests}

The specimens for metallographic analysis were prepared along a routine procedure followed by a final polishing with an oxide polish suspension compound (OPS). The specimens were etched prior to optical microscopy investigations to determine geometrical features of the welds. Visual inspections were also used to analyze the outer appearance of the weld seams to examine for weld imperfections, e.g., underfill, undercut, spatter and excess of penetration.

The microstructures of the laser beam welded butt joints were also investigated using scanning electron microscopy (SEM) (Jeol JSM6490LV) equipped with back-scattered electron (BSE), energy-dispersive X-ray spectroscopy (EDX), and electron back-scatter diffraction
Table 1

Chemical composition (wt.\%) of the investigated high entropy alloy determined by EDX analysis.

\begin{tabular}{llllllll}
\hline $\mathrm{Al}$ & $\mathrm{Si}$ & $\mathrm{S}$ & $\mathrm{Cr}$ & $\mathrm{Mn}$ & $\mathrm{Fe}$ & $\mathrm{Co}$ & $\mathrm{Ni}$ \\
\hline 2.64 & 0.16 & 0.23 & 18.48 & 11.03 & 21.99 & 21.82 & 23.65 \\
\hline
\end{tabular}

(EBSD) (EDAX TSL OIM) detectors to produce images and determine the local chemical composition, micro-texture, phase contents and grain sizes. The EDX scanning over a large area $\left(\sim 1 \times 1 \mathrm{~mm}^{2}\right)$ was used to measure the chemical composition of the alloy (Table 1). In addition, $0.15 \mathrm{wt} \%$ of carbon was determined in the alloy with Leco analyzer. The EBSD measurements were performed at $30 \mathrm{kV}$, an emission current of $75 \mu \mathrm{A}$, a sample tilt angle of $70^{\circ}$, a working distance of $14 \mathrm{~mm}$, a magnification of $100 \times$ and a step size of $2.0 \mu \mathrm{m}$. The size of scan area was $950 \mu \mathrm{m} \times 950 \mu \mathrm{m}$. The orientation calculation was based on the GSHE method, where triclinic sample symmetry could be assumed.

The samples for transmission electron microscopy (TEM) analysis were prepared by conventional twin-jet electro-polishing of mechanically pre-thinned to $100 \mu \mathrm{m}$ foils, in a mixture of $95 \% \mathrm{C}_{2} \mathrm{H}_{5} \mathrm{OH}$ and $5 \%$ $\mathrm{HClO}_{4}$ at a $27 \mathrm{~V}$ potential. TEM investigations were performed using a JEOL JEM-2100 microscope with an accelerating voltage of $200 \mathrm{kV}$ equipped with an EDX detector. The volume fractions and average sizes of the second phase(s) particles were measured by a Digimizer Image Analysis Software using TEM images.

Microhardness profiles across the joint were obtained using an automated Vickers hardness testing machine with a $0.5 \mathrm{~kg}$ load (HV 0.5).

\section{Results and discussion}

\subsection{Structure and composition of the base material}

The microstructure of the alloy produced by self-propagating hightemperature synthesis consisted of dendritic grains containing many inclusions (Fig. 1). The EDX analysis conducted for the base material (BM) and the inclusions (Tables 1 and 2) detected the following elements: $\mathrm{Al}, \mathrm{Si}, \mathrm{S}, \mathrm{Cr}, \mathrm{Mn}, \mathrm{Fe}, \mathrm{Co}$ and $\mathrm{Ni}$ (Table 1). The alloy contained $\sim 18-24 \mathrm{wt} \%$ of $\mathrm{Co}, \mathrm{Cr}, \mathrm{Fe}$, and $\mathrm{Ni}, 11.03 \%$ of $\mathrm{Mn}, 2.64 \%$ of $\mathrm{Al}$, and $0.16-0.23 \%$ of $S$ and $\mathrm{Si}$. Although carbon is presented in the alloy (see Section 2.2) it was not detected most possibly due to limited resolution of the used SEM-EDX system. The EDX analysis of inclusions (which are seen as dark particles in the BSE-contrast images, Fig. 1) showed that there were MnS-particles (Table 2).

As previously mentioned, the BM exhibited a dendritic microstructure with the average major axis length of $(285.6 \pm 53.2) \mu \mathrm{m}$, the

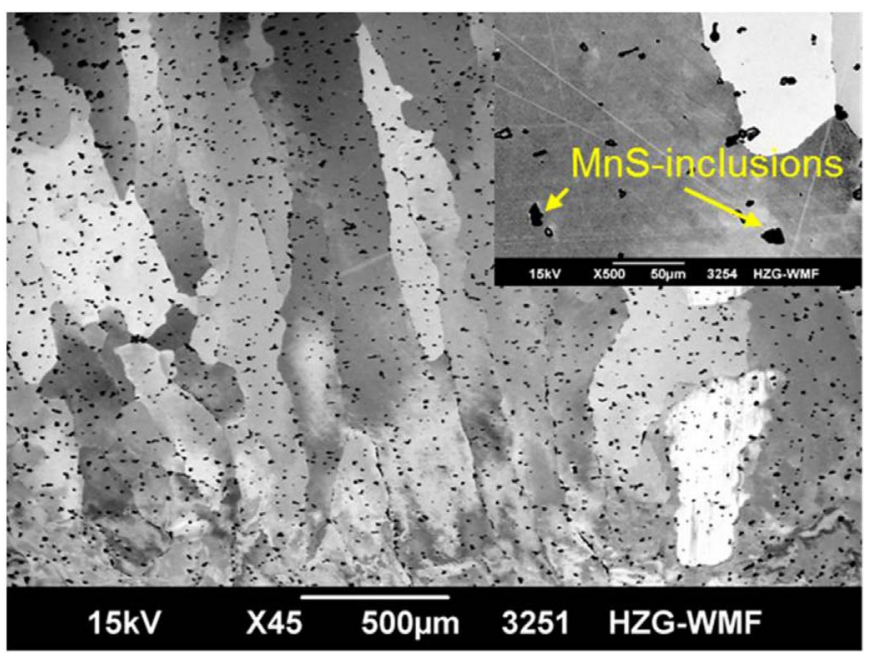

Fig. 1. BSE image of the base material microstructure. 
Table 2

Chemical composition (wt.\%) of MnS-inclusions (indicated with arrows in Fig. 1) determined by EDX analysis.

\begin{tabular}{llllllll}
\hline $\mathrm{Al}$ & $\mathrm{Si}$ & $\mathrm{S}$ & $\mathrm{Cr}$ & $\mathrm{Mn}$ & $\mathrm{Fe}$ & $\mathrm{Co}$ & $\mathrm{Ni}$ \\
\hline 0.15 & 0.24 & 18.15 & 35.46 & 33.42 & 6.03 & 3.67 & 2.87
\end{tabular}

minor axis length of $(98.4 \pm 17.6) \mu \mathrm{m}$ and the average aspect ratio of $0.3 \pm 0.1$ (Fig. 2a). An orientation band between $<103>/ / \mathrm{ND}$ and $<229>/ / \mathrm{ND}$, as well as $<111>/ / \mathrm{ND}$ can be clearly seen (Fig. 2b). The mean misorientation angle was $35.6^{\circ}$. The microstructure also consisted of low-angle grain boundaries.

The TEM investigations (Fig. 3) demonstrated the presence of rectangular second phase particles with clear interfaces. The average length and width of the particles were $(130 \pm 60) \mathrm{nm}$ and $(50 \pm 20)$ $\mathrm{nm}$, respectively. Most of the particles were organized in chains (Fig. 3a). The analysis of the crystal structure of the particles via selected area electron diffraction patterns (SAEDs) has revealed that they were $\mathrm{M}_{23} \mathrm{C}_{6}$ type carbides. According to the results of the chemical analysis, the metallic part of the carbides was almost exclusively composed of Cr. Note that the energy resolution of the TEM-EDX system used in the current study was insufficient to reliably measure the concentration of carbon due to low atomic weight.

\subsection{Structure after the welding}

A set of experiments with a laser power level of $2.0 \mathrm{~kW}$ and four welding speeds $(3.0 \mathrm{~m} / \mathrm{min}, 4.0 \mathrm{~m} / \mathrm{min}, 5.0 \mathrm{~m} / \mathrm{min}$ and $6.0 \mathrm{~m} / \mathrm{min})$ was performed to identify the appropriate welding parameters to produce butt joints with full penetration and regular shapes. During the LBW experiments the formation of a welding plume, indicating the evaporation of the material was observed. This might be one of the reasons for the formation of the underfill which is seen in the cross-section of the butt joint laser beam welded with a welding speed of $5 \mathrm{~m} / \mathrm{min}$ (Fig. 4a). The detrimental effect of the underfill is that some mechanical properties of butt joints can be reduced. The boundary between the joint coupons as well as the boundary of the fusion zone (FZ) are clearly seen in Fig. 4a. The weld seam width was $\sim 570 \mu \mathrm{m}$. Welding defects such as pores or cracks were not identified.

To analyze the influence of the welding speed on the weld shape, the widths of the FZ were measured in the cross-sections of the butt joints at three different positions: radiation exposure side, middle of the weld and weld root side. The results are shown in Fig. 4b. LBW at the welding speed of $3 \mathrm{~m} / \mathrm{min}$ led to a large $\mathrm{FZ}$ width at the radiation exposure side. At the welding speed of $6 \mathrm{~m} / \mathrm{min}$ the $\mathrm{FZ}$ width at the weld root side of $300 \mu \mathrm{m}$ was obtained. An increase in the welding speed above $6 \mathrm{~m} / \mathrm{min}$ led to a partial penetration while a decrease in the welding speed below $3 \mathrm{~m} / \mathrm{min}$ resulted in the formation of a wide weld seam. The results shown in the diagram (Fig. 4b) indicate, that weld with a more "cylindrical" shape ("I"-shape) can be achieved at welding speeds in the range between $4 \mathrm{~m} / \mathrm{min}$ and $5 \mathrm{~m} / \mathrm{min}$. The "cylindrical" shape can be advantageous for tensile properties of the weld.

All butt joints showed a non-symmetrical weld shape (Fig. 4a) most likely due to coarse columnar grains of the base material. Since welding at $5 \mathrm{~m} / \mathrm{min}$ showed more regular shape, this butt joint was used in further microstructural investigations of this study.

\section{(a)}

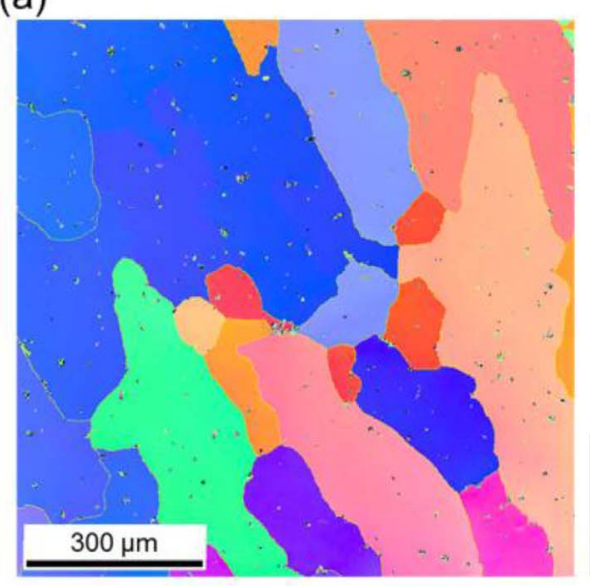

(b)

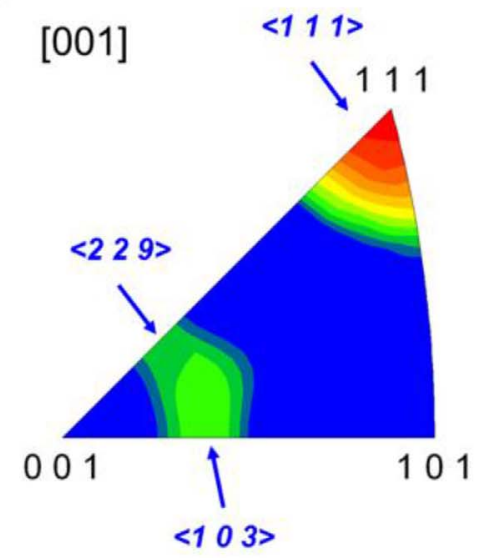

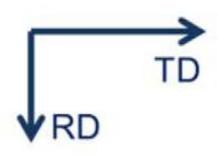

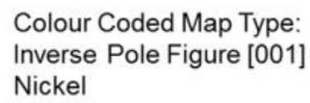

Colour Coded Map Type: Inverse Pole Figure [001] Nickel

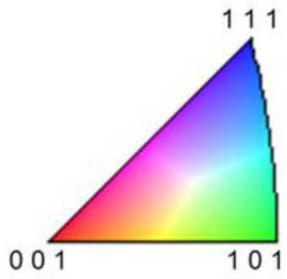

Boundaries: Rotation Angle Min Max Fraction Number Length

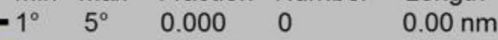

$\begin{array}{lllll}6^{\circ} & 180^{\circ} & 0.999 & 10702 & 1.24 \\ \mathrm{~cm}\end{array}$

Texture Name: Harmonic: L=22, HW=5.0

Calculation Method: Harmonic Series Expansion

Series Rank (I): 22

Gaussian Smoothing: $5.0^{\circ}$

Sample Symmetry: Triclinic

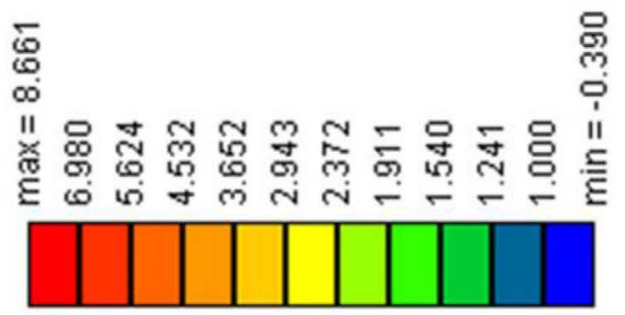

Fig. 2. EBSD analysis of the base material: (a) crystal orientation map and (b) [001] inverse pole figure. 


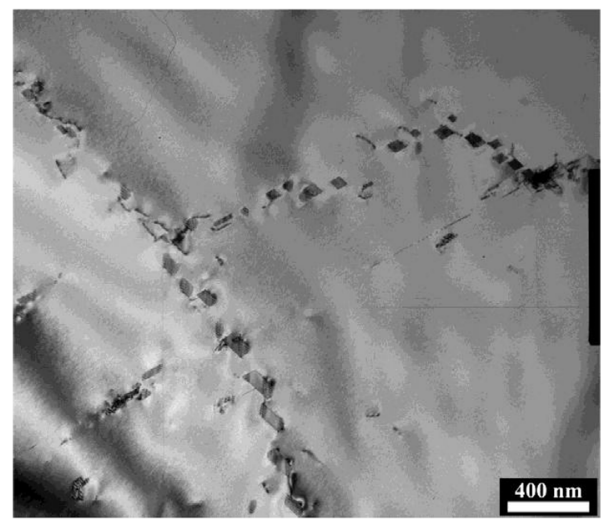

(a)

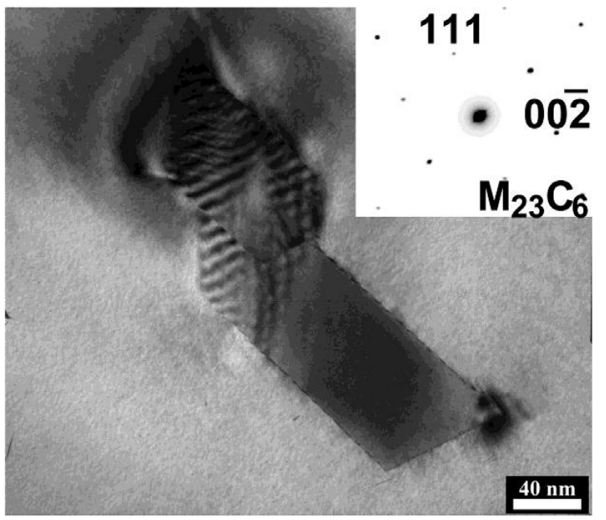

(b)

Fig. 3. TEM bright-field images of the base material. Selected area electron diffraction pattern (SAED) of the precipitate is shown in (b).
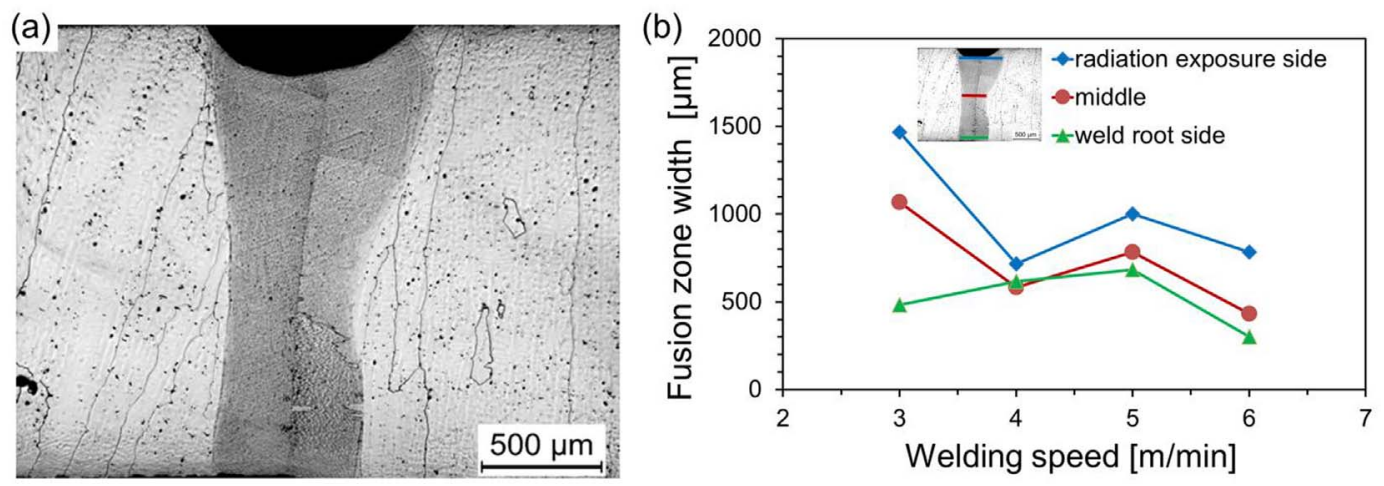

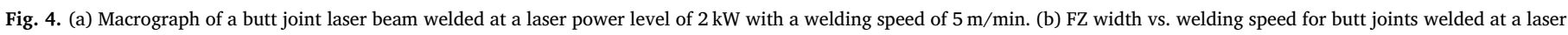
power level of $2 \mathrm{~kW}$.

Differences in microstructure and grain orientation distributions between the BM, heat-affected zone (HAZ) and the FZ were not significant (Figs. 2 and 5). The grains showed the average major axis length of $(408.8 \pm 28.0) \mu \mathrm{m}$ and the minor axis length of $(151.3 \pm 25.6) \mu \mathrm{m}$ with the average aspect ratio of $(0.4 \pm 0.1)$ in both cases of HAZ and FZ. Some small grains were detected along the solidification front (Fig. 5a). The average values of misorientation angles were $26.7^{\circ}$ and $36.9^{\circ}$ for the HAZ and FZ, respectively. Changes in the crystal orientation bands were observed in the HAZ/FZ transition area. An orientation band $<103>/ /$ ND was observed in the HAZ (Fig. 5b). Also a reduction in axial intensities from $7.2 \mathrm{mrd}$ to $2.8 \mathrm{mrd}$ was observed (Fig. 5c) most probably due to smaller grains which from in the FZ in comparison with those in the HAZ.

The differences were obtained in the image quality (IQ) values, i.e., $\mathrm{IQ}=6599 \pm 1167$ for the BM, IQ $=4105 \pm 1074$ for the HAZ and $\mathrm{IQ}=3905 \pm 1139$ for the FZ (Fig. 6a-c). The IQ value is determined using the contrast and brightness of a Kikuchi diffraction image. The Kikuchi diffraction image is used for the identification of the crystal plane (hkl) and determination of the Euler angles $(\varphi 1, \varphi 2, \varphi 3)$, which is affected by the density of the defects. The high density of defects reduces the brightness and contrast of the Kikuchi diffraction image and thus the IQ-value. Therefore, the lower IQ-values for the HAZ and the FZ indicate that through the laser beam welding, the density of defects in the fcc matrix increased.

Fig. 7 demonstrates the results of TEM examination of the FZ. Two types of precipitates were found in the fcc matrix (Fig. 7a). The first one was relatively coarse (the average diameter was $(110 \pm 40) \mathrm{nm}$ ) $\mathrm{M}_{23} \mathrm{C}_{6}$ carbides with a nearly spherical shape (Fig. 7b). Their chemical composition did not noticeably differ from that of carbides in the BM. The second type of the particles were nano-sized particles with the B2 structure (Fig. 7c and d). Their fraction and the average diameter were $\sim 4 \%$ and $\sim 5 \mathrm{~nm}$, respectively. Due to very small size it was impossible to determine reliably the chemical composition of the $\mathrm{B} 2$ precipitates by the TEM-EDX analysis. However it should be noted, that some B2 precipitate-free areas can be found around carbide particles (Fig. 7b).

\subsection{Microhardness profile}

The microhardness profiles (Fig. 8) were determined across the weld in three regions of the cross-section: the radiation exposure side, middle of the weld and weld root side. An increase in microhardness occurred within the HAZ from the BM to the FZ. The average microhardness values for the BM and FZ of the specimens were $(153 \pm 3) \mathrm{HV} 0.5$ and $(208 \pm 6) \mathrm{HV} 0.5$, respectively.

\section{Discussion}

The presented data demonstrated feasibility of (i) production of the CoCrFeNiMn-type high entropy alloy by self-propagating high-temperature synthesis (SHS) and (ii) successful fiber laser beam welding (LBW) of the produced alloy. The chemical composition of the present alloy differs from that of the well-studied equiatomic CoCrFeNiMn HEA. Also, in addition to anticipated changes in structure and texture of the fcc matrix of the alloy due to remelting, welding resulted in (i) precipitation of the nanoscale B2 phase particles and (ii) significant increase in the microhardness of the FZ. These features deserve more detailed discussion.

The mentioned difference in the chemical composition between the alloy used in the current study (Table 1 , also contains $0.15 \mathrm{wt} \%$ of C) and the "classical" Cantor's alloy is most likely associated with the using 
(a)

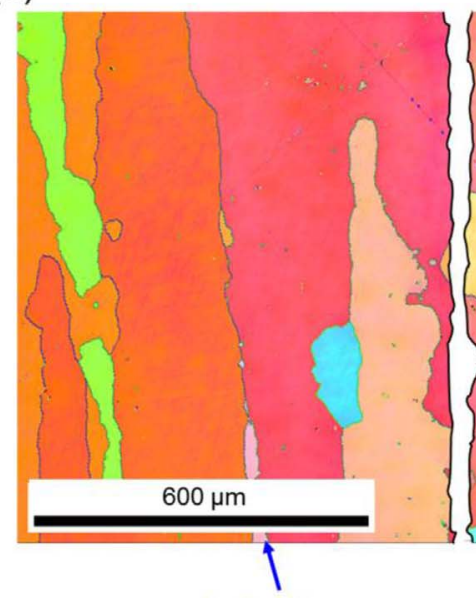

fusion line

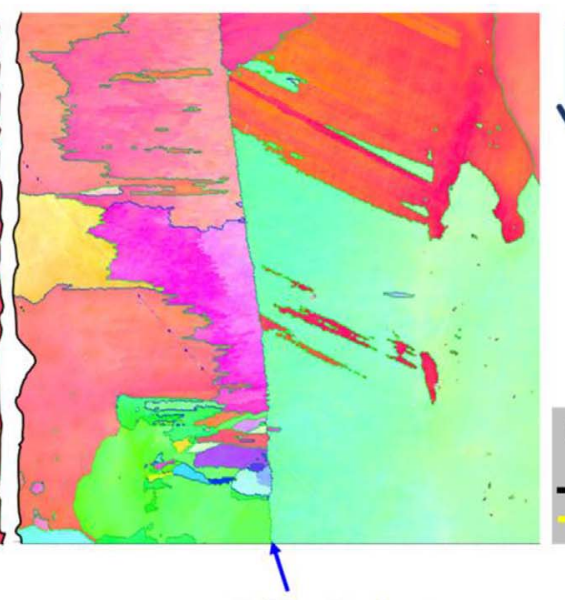

solidification front

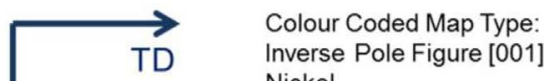

Nickel
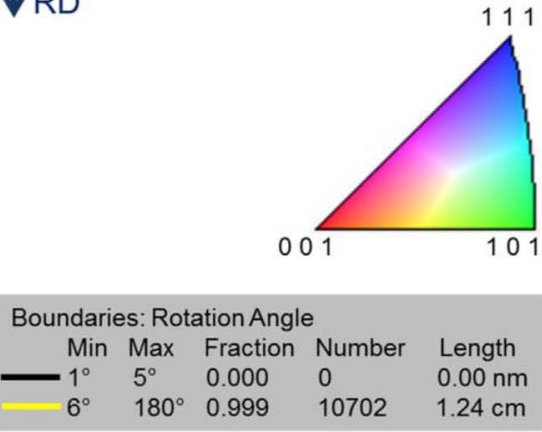

(b)

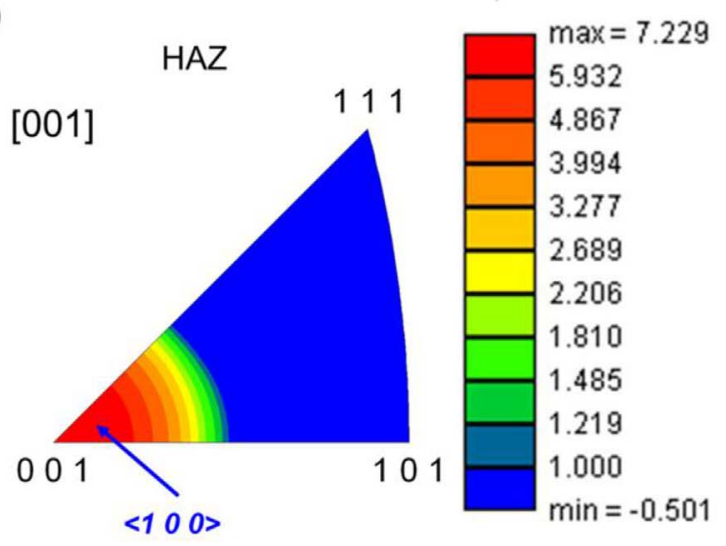

(c)

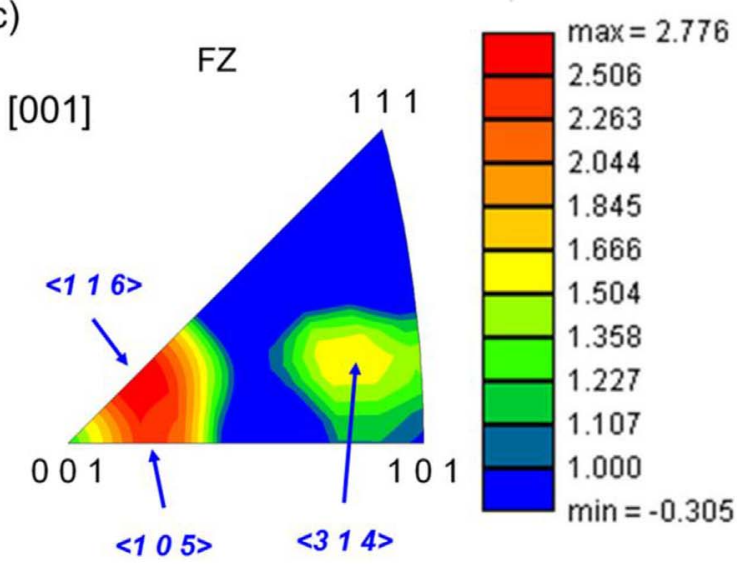

Texture Name: Harmonic: $\mathrm{L}=22, \mathrm{HW}=5.0$

Gaussian Smoothing: $5.0^{\circ}$

Calculation Method: Harmonic Series Expansion Sample Symmetry: Triclinic Series Rank (I): 16

Fig. 5. Butt joint cross section: (a) crystal orientation map and inverse pole figures of (b) HAZ and (c) FZ.

oxides of the constitutive elements ( $\mathrm{Co}, \mathrm{Cr}, \mathrm{Fe}, \mathrm{Ni}, \mathrm{Mn}$ ) and $\mathrm{Al}_{2} \mathrm{O}_{3}$ oxide for ignition during SHS. The presence of the aluminum oxide in starting powders is obviously the reason for presenting $2.64 \mathrm{wt} \%$ of $\mathrm{Al}$ in the alloy (Table 1). Due to high volatility [12,14], approximately a half of $\mathrm{Mn}$ is suggested to be lost during the high-temperature (estimated temperature $\approx 2200-2300^{\circ} \mathrm{C}$ ) SHS reaction thereby resulting in $\sim 2$ times lower content in comparison with that of other principal metallic elements (Co, Cr, Fe and Ni) (Table 1). In future efforts extra amount of manganese should probably be used in the initial products to obtain equiatomic alloy via the SHS method. The presence of contaminants like C, S, and Si was most likely originated from the impurity of initial oxide powders.

Formation of the MnS particles can be attributed to highly negative enthalpy of the MnS compounds formation $(\sim-200 \mathrm{~kJ} / \mathrm{mol}$ at room temperature [48]). The effect of MnS (as well as other inclusions) on properties of the CoCrFeNiMn-type HEAs has never been studied, but MnS are well known as wholesome inclusions in steel products $[49,50]$. For example $\mathrm{Mn}$ is often added to steels to prevent the formation of brittle iron sulphides which considerably decrease the hot formability [50]. MnS is much softer and therefore does not cause a drastic decrease
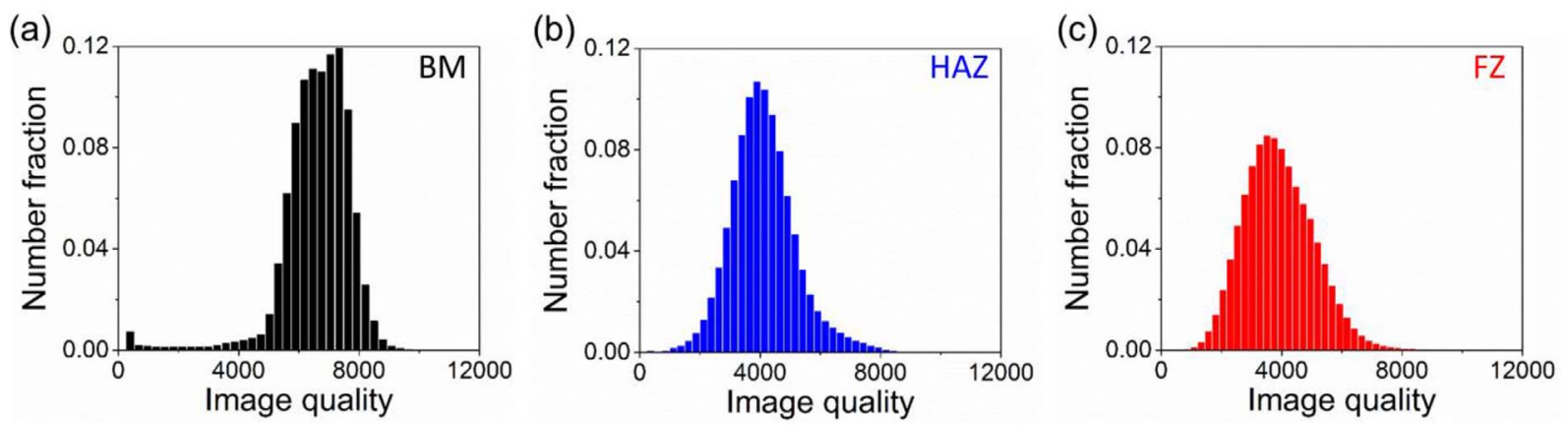

Fig. 6. Number fraction vs. image quality diagrams of (a) BM, (b) HAZ and (c) FZ. 


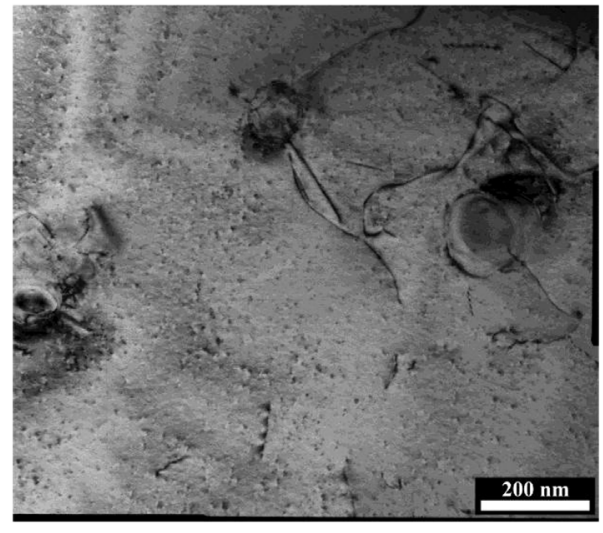

(a)

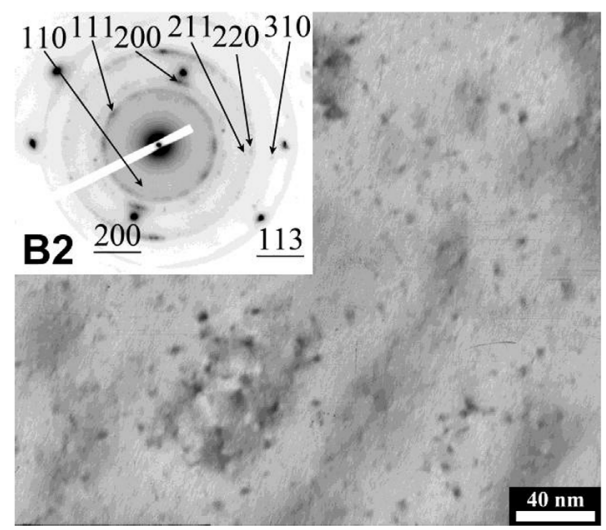

(c)

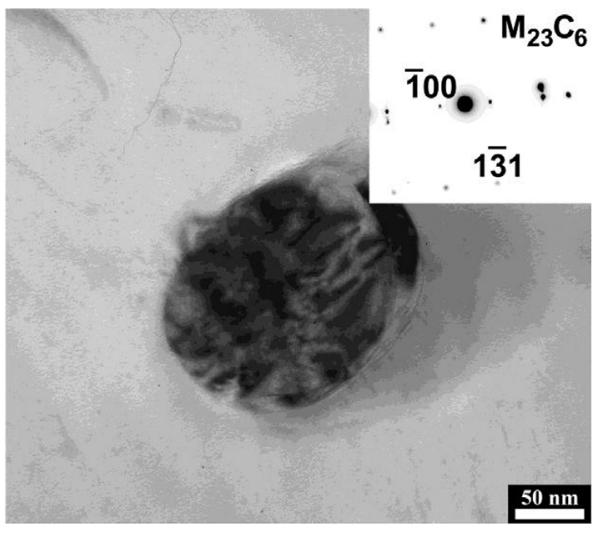

(b)

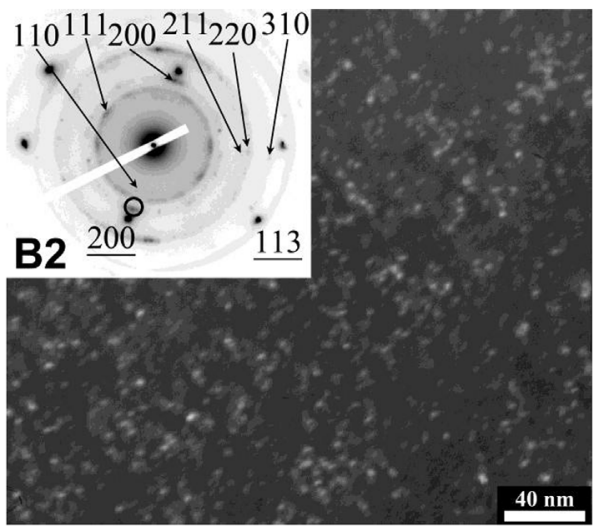

(d)

Fig. 7. TEM bright-field (a-c) and dark-field (d) images of the fusion zone. Selected area electron diffraction patterns (SAED) of precipitates are shown in (b, c, d).

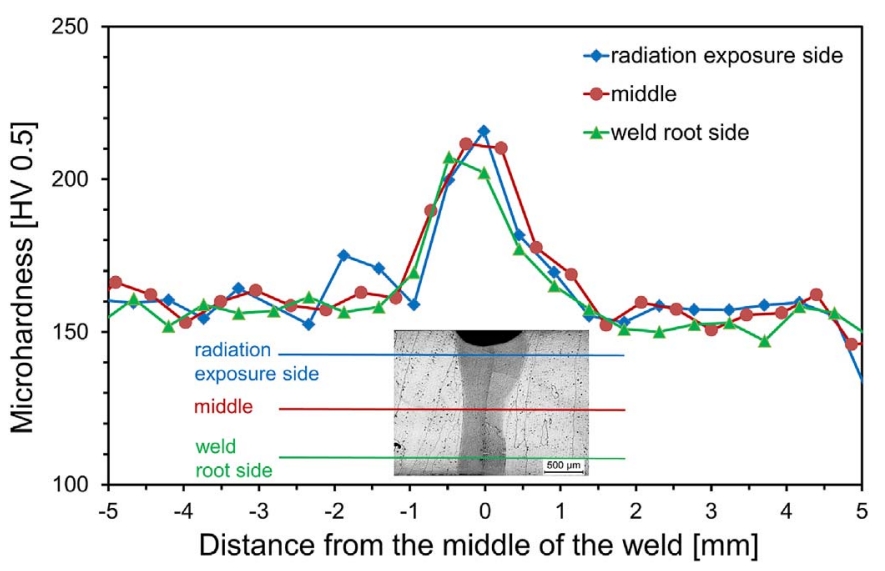

Fig. 8. Microhardness profile of a butt joint laser beam welded at a laser power level of $2 \mathrm{~kW}$ with a welding speed of $5 \mathrm{~m} / \mathrm{min}$.

in properties, although crack initiation and propagation are often promoted by these inclusions. The effect of MnS on mechanical properties of the CoCrFeNiMn-type alloy will be studied comprehensively in prospective investigations.

A traditional tool for the understanding of phase formations in metallic alloys is phase diagrams. Unfortunately, experimental phase diagrams for compositionally complex HEAs are mostly unavailable. Equilibrium phase diagrams for multicomponent alloys can be produced using the CALPHAD method. In present work, we have employed a ThermoCalc (v. 2017a) software with recently introduced a TCHEA2 database, specifically created for HEAs. However, the TCHEA2 database does not include sulphur, and therefore cannot be used for the

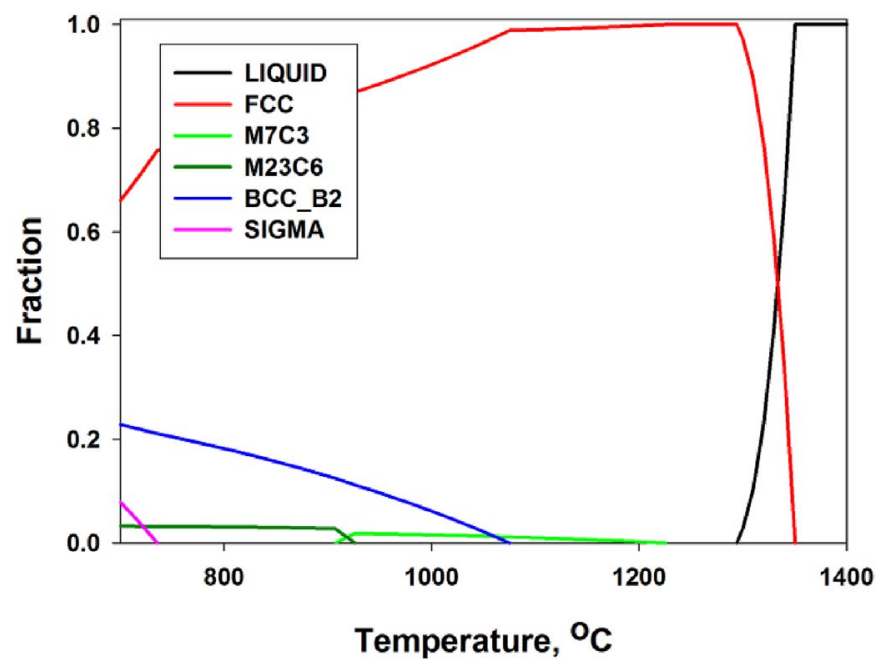

Fig. 9. Calculated equilibrium phase diagram of the program alloy (the composition used for the calculation was (in wt.\%) Ni-23.73; Fe-21.99; Co-21.82; Cr-18.48; Mn-11.03; Al2.64; Si-0.16; C-0.15).The chemical composition of the alloy was mostly taken from Table 1; $0.15 \mathrm{wt} \%$ of $\mathrm{C}$ and $0.08 \mathrm{wt} \%$ of Ni were added to compensate the absence of $\mathrm{S}$ (not included in TCHEA2 database).

prediction of the $\mathrm{Mn}_{2} \mathrm{~S}$ particles which were found in the experimental alloy. Nevertheless $\mathrm{Al}, \mathrm{C}$, and $\mathrm{Si}$ are included in the database and the presence of second phases caused by these contaminants can be predicted. The constructed phase diagram is shown in Fig. 9.

The calculated phase diagram suggests that the alloy solidified through a single fcc phase. The liquidus and solidus temperatures of the alloy were $\approx 1350{ }^{\circ} \mathrm{C}$ and $\approx 1290{ }^{\circ} \mathrm{C}$ respectively. Shortly after 
solidification, precipitation of $\mathrm{M}_{7} \mathrm{C}_{3}$ carbides (the solvus temperature $\approx 1225^{\circ} \mathrm{C}$ ) was predicted. These carbides can be roughly described as the $\mathrm{Cr}_{7} \mathrm{C}_{3}$, since they contain 56-70 (at. \%) $\mathrm{Cr}$ and 30 (at. \%) C. At temperatures in the range $910-925^{\circ} \mathrm{C}$ the $\mathrm{M}_{7} \mathrm{C}_{3}$ carbides transformed to $\mathrm{M}_{23} \mathrm{C}_{6}$ carbides. The $\mathrm{M}_{23} \mathrm{C}_{6}$ carbides were also composed almost exclusively of $\mathrm{Cr}$ and $\mathrm{C}$. Nevertheless, the fraction of the carbides in the alloy did not increase pronouncedly with temperature decreasing and did not exceed 0.033 . At $\approx 1075^{\circ} \mathrm{C}$ a B2 phase precipitated from the fcc phase as well. The B2 phase was mostly composed of Ni (26-32 at.\%) and $\mathrm{Al}(16-26$ at.\%). The fraction of this phase increased rapidly with decreasing temperature reaching 0.23 at $700{ }^{\circ} \mathrm{C}$. Finally, at $735{ }^{\circ} \mathrm{C}$ a sigma phase formed. This phase was mostly composed of $\mathrm{Cr}$ and $\mathrm{Fe}$ and its fraction reached 0.08 at $700{ }^{\circ} \mathrm{C}$. Note that $\mathrm{Si}$ remained completely dissolved in the fcc phase even at $700^{\circ} \mathrm{C}$.

The calculated phase diagram agreed reasonably with the experimental data. For instance, the base (as-sintered) material was composed of the fcc matrix with the $\mathrm{M}_{23} \mathrm{C}_{6}$ carbides ( $\mathrm{MnS}$ inclusions were not taken into consideration) (Figs. 1-3). This structure agrees reasonably well with the phase diagram (Fig. 9) suggesting however that diffusion was not arrested immediately after the solidification leading to restricted precipitation of the carbides (predicted to occur at the temperature only $\approx 65^{\circ} \mathrm{C}$ lower than the solidus of the fcc phase). The carbides found in the as-sintered alloy were very stable - the remelting of the material during laser welding resulted in their spheroidization only (compare Figs. 3b and $7 \mathrm{~b}$ for example). Therefore, it might be suggested that the $\mathrm{M}_{23} \mathrm{C}_{6}$ carbides precipitated directly from the fcc solid solution without formation of the intermediate $\mathrm{M}_{7} \mathrm{C}_{3}$ phase contrary to the thermodynamic prediction (Fig. 9). This discrepancy can be attributed to the well-known imperfections of the available thermodynamic databases [1].

A plenty of the very fine B2 precipitates appeared in the microstructure of the FZ after LBW (Fig. 7). The observed structure of the welded alloy was consistent with the predicted phase fields in the 735-910 ${ }^{\circ} \mathrm{C}$ temperature interval (i.e. the lower-temperature part of the phase diagram (Fig. 9) in comparison with the fcc + carbides phase fields of the sintered alloy). It might seem surprising, as the cooling rates after laser beam welding are expected to be much higher than that after the SHS process. However, one must keep in mind that the temperature of the melted material is likely to be much higher during the SHS process than that during laser welding. Therefore, most probably, the structure of the weld corresponded to the equilibrium at lower temperature. Fast cooling rates, in turn, retard diffusion thereby reducing the size of the B2 precipitates (Fig. 7c and d) [51].

The microhardness of the base material (153 HV) (Fig. 8) agreed reasonably well with the reported values of the microhardness of the precipitate-free CoCrFeNiMn alloy $(160 \mathrm{HV}$ in the as-cast condition [22]). This finding implies that the MnS inclusions and the $\mathrm{M}_{23} \mathrm{C}_{6}$ carbides found in the as-cast condition of the studied alloy did not cause noticeable strengthening. The latter can be associated with either big size (MnS inclusions) or low volume fraction and non-random arrangement $\left(\mathrm{M}_{23} \mathrm{C}_{6}\right.$ carbides) of these phases.

Contrary, the observed phase transformation, i.e. the nano-sized B2 particles precipitation, can potentially be the reason for the increase of the hardness of the alloy after welding (Fig. 8) to 208 HV. To check this suggestion, the estimation of the strengthening effect of the B2 precipitates was done using the well-known Ashby-Orowan equation [52]:

$\Delta \sigma=0.538 \mathrm{~Gb}\left(\frac{\sqrt{f}}{d}\right) \operatorname{In}\left(\frac{d}{2 b}\right)$,

where $G$ is the shear modulus, $b$ is the Burgers vector, $f$ is the volume fraction of particles, and $d$ is their diameter. The fraction and diameter of the particles were 0.04 and $5 \mathrm{~nm}$, respectively. The values of $G=81 \mathrm{GPa}$ and $b=0.254 \mathrm{~nm}$ as reported in Ref. [53] for the CoCrFeNiMn equiatomic alloy were used. After converting the calculated strengthening $\Delta \sigma$ to $\mathrm{HV}$, we have obtained $\Delta H V \approx 100 \mathrm{HV}$. This value is reasonably close to the experimental increase of microhardness $(\Delta H V=65 \mathrm{HV})$. Possibly, somewhat lower experimental increase of microhardness can be caused by the absence of the B2 particles in some areas (Fig. 7b). As a summary, the calculations demonstrate that the increased hardness after laser beam welding can be associated with the precipitation of the nano-sized B2 phase particles.

The obtained results have demonstrated not only feasibility of the SHS process for the fabrication of the CoCrFeNiMn-type HEA and fiber LBW for the effective joining of the alloy, but also a pronounced hardness increase in the fusion zone due to the precipitation of the B2 particles. Weld joints are often considered as "weak" areas of fabricated structures, so the higher hardness (strength) in the fusion zone of the laser beam welded CoCrFeNiMn-type alloy can potentially be an advantage for a practical application. The important fact is that the hardened joint was produced directly after welding, i.e. no specific postwelding processing was required. It means that the alloy hardens due to the "natural" heat treatment during welding, i.e melting and rapid cooling. Other laser processing technologies, including additive manufacturing technologies, can also benefit from such "intrinsic" hardening [54]. Perhaps, hardening response can be controlled both by the processing conditions (i.e. laser power, welding speed, etc. [51]) and the composition of the alloy (i.e. Al concentration [55,56]). This finding can open the way for designing of HEAs with "intrinsic" hardening capability during laser processing, including, but not limited to, laser beam welding and laser additive manufacturing.

\section{Conclusion}

1. CoCrFeNiMn-type high entropy alloy was successfully fabricated using self-propagating high-temperature sintering (SHS) process. The alloy had reduced Mn content and contains impurities including $\mathrm{Al}, \mathrm{C}, \mathrm{S}$, and Si. Structural investigations had revealed that the alloy was composed of coarse columnar grains with fcc structure. Coarse $\mathrm{MnS}$ inclusions and fine $\mathrm{M}_{23} \mathrm{C}_{6}$ carbides were also found.

2. Successful fiber laser beam welding of the CoCrFeNiMn-type high entropy alloy using the laser power of $2 \mathrm{~kW}$ was demonstrated. Sound welds without visible defects such as porosity or cracks were produced. The difference in microstructure and grain orientation distribution between the base material, heat-affected zone and the fusion zone was not significant. The EBSD analysis suggested an increased density of defects in the fcc matrix in the heat affected zone as well as in the fusion zone in comparison to the base material. In addition, precipitation of the nano-scale (average diameter of $5 \mathrm{~nm}$ ) B2 phase particles was observed. The formation of the B2 precipitates after welding was found to be in a reasonable agreement with the equilibrium phase diagram of the alloy produced using the ThermoCalc software and the TCHEA2 database.

3. The microhardness measurements have revealed a significant increase of the microhardness from $(153 \pm 3) \mathrm{HV} 0.5$ in the base material to $(208 \pm 6) \mathrm{HV} 0.5$ in the fusion zone. The increase in the microhardness was attributed to the precipitation of the nanoscale B2 particles.

\section{Acknowledgements}

The authors would like to thank Mr. R. Dinse, Mr. P. Haack and Mr. F. Dorn from Helmholtz-Zentrum Geesthacht for their valuable technical support. The authors are also grateful to the personnel of the Joint Research Center, "Technology and Materials", Belgorod State National Research University, for their assistance with the instrumental analysis. This work was supported by Russian Foundation for Basic Research (grants №16-38-60061 and №16-08-00398).

\section{References}

[1] D.B. Miracle, O.N. Senkov, A critical review of high entropy alloys and related 
concepts, Acta Mater. 122 (2017) 448-511, http://dx.doi.org/10.1016/j.actamat. 2016.08.081.

[2] Y. Zhang, T.T. Zuo, Z. Tang, M.C. Gao, K.A. Dahmen, P.K. Liaw, Z.P. Lu, Microstructures and properties of high-entropy alloys, Prog. Mater. Sci. 61 (2014), http://dx.doi.org/10.1016/j.pmatsci.2013.10.001.

[3] E.J. Pickering, N.G. Jones, High-entropy alloys: a critical assessment of their founding principles and future prospects, Int. Mater. Rev. (2016) 183-202, http:// dx.doi.org/10.1080/09506608.2016.1180020.

[4] M.H. Tsai, J.W. Yeh, High-entropy alloys: a critical review, Mater. Res. Lett. 2 (2014) 107-123, http://dx.doi.org/10.1080/21663831.2014.912690.

[5] J.W. Yeh, S.K. Chen, S.J. Lin, J.Y. Gan, T.S. Chin, T.T. Shun, C.H. Tsau, S.Y. Chang, Nanostructured high-entropy alloys with multiple principal elements: novel alloy design concepts and outcomes, Adv. Eng. Mater. 6 (2004) 299-303, http://dx.doi. org/10.1002/adem.200300567.

[6] S. Gorsse, D.B. Miracle, O.N. Senkov, Mapping the world of complex concentrated alloys, Acta Mater. 135 (2017) 177-187, http://dx.doi.org/10.1016/j.actamat. 2017.06.027.

[7] D. Miracle, J. Miller, O. Senkov, C. Woodward, M. Uchic, J. Tiley, Exploration and development of high entropy alloys for structural applications, Entropy 16 (2014) 494-525, http://dx.doi.org/10.3390/e16010494.

[8] O.N. Senkov, J.D. Miller, D.B. Miracle, C. Woodward, Accelerated exploration of multi-principal element alloys with solid solution phases, Nat. Commun. 6 (2015) 6529, http://dx.doi.org/10.1038/ncomms7529.

[9] D. Miracle, B. Majumdar, K. Wertz, S. Gorsse, New strategies and tests to accelerate discovery and development of multi-principal element structural alloys, Scripta Mater. 127 (2017) 195-200, http://dx.doi.org/10.1016/j.scriptamat.2016.08.001.

[10] B. Cantor, I.T.H. Chang, P. Knight, A.J.B. Vincent, Microstructural development in equiatomic multicomponent alloys, Mater. Sci. Eng. A 375 (2004) 213-218, http:// dx.doi.org/10.1016/j.msea.2003.10.257.

[11] M. Laurent-Brocq, A. Akhatova, L. Perrière, S. Chebini, X. Sauvage, E. Leroy, Y. Champion, Insights into the phase diagram of the CrMnFeCoNi high entropy alloy, Acta Mater. 88 (2015), http://dx.doi.org/10.1016/j.actamat.2015.01.068.

[12] F. Otto, Y. Yang, H. Bei, E.P.P. George, Relative effects of enthalpy and entropy on the phase stability of equiatomic high-entropy alloys, Acta Mater. 61 (2013) 2628-2638, http://dx.doi.org/10.1016/j.actamat.2013.01.042.

[13] G.A. Salishchev, M.A. Tikhonovsky, D.G. Shaysultanov, N.D. Stepanov, A.V. Kuznetsov, I.V. Kolodiy, A.S. Tortika, O.N. Senkov, Effect of Mn and v on structure and mechanical properties of high-entropy alloys based on CoCrFeNi system, J. Alloy. Comp. 591 (2014) 11-21, http://dx.doi.org/10.1016/j.jallcom. 2013.12.210.

[14] F. Otto, A. Dlouhý, C. Somsen, H. Bei, G. Eggeler, E.P. George, The influences of temperature and microstructure on the tensile properties of a CoCrFeMnNi highentropy alloy, Acta Mater. 61 (2013), http://dx.doi.org/10.1016/j.actamat.2013. 06.018

[15] B. Gludovatz, A. Hohenwarter, D. Catoor, E.H. Chang, E.P. George, R.O. Ritchie, A fracture-resistant high-entropy alloy for cryogenic applications, Science (80-. ) 345 (2014), http://dx.doi.org/10.1126/science.1254581.

[16] A. Gali, E.P. George, Tensile properties of high- and medium-entropy alloys, Intermetallics 39 (2013) 74-78, http://dx.doi.org/10.1016/j.intermet.2013.03 018.

[17] Z. Zhang, M.M. Mao, J. Wang, B. Gludovatz, Z. Zhang, S.X. Mao, E.P. George, Q. Yu, R.O. Ritchie, Nanoscale origins of the damage tolerance of the high-entropy alloy CrMnFeCoNi, Nat. Commun. 6 (2015) 10143, http://dx.doi.org/10.1038/ ncomms10143.

[18] G. Laplanche, A. Kostka, O.M.M. Horst, G. Eggeler, E.P.P. George, Microstructure evolution and critical stress for twinning in the CrMnFeCoNi high-entropy alloy, Acta Mater. 118 (2016) 152-163, http://dx.doi.org/10.1016/j.actamat.2016.07. 038.

[19] B. Gludovatz, A. Hohenwarter, K.V.S. Thurston, H. Bei, Z. Wu, E.P. George, R.O. Ritchie, Exceptional damage-tolerance of a medium-entropy alloy CrCoNi at cryogenic temperatures, Nat. Commun. (2016), http://dx.doi.org/10.1038/ ncomms10602.

[20] G. Laplanche, A. Kostka, C. Reinhart, J. Hunfeld, G. Eggeler, E.P. George, Reasons for the superior mechanical properties of medium-entropy CrCoNi compared to high-entropy CrMnFeCoNi, Acta Mater. (2017), http://dx.doi.org/10.1016/j. actamat.2017.02.036.

[21] N.D. Stepanov, D.G. Shaysultanov, R.S. Chernichenko, N.Y. Yurchenko, S.V. Zherebtsov, M.A. Tikhonovsky, G.A. Salishchev, Effect of thermomechanical processing on microstructure and mechanical properties of the carbon-containing CoCrFeNiMn high entropy alloy, J. Alloy. Comp. 693 (2017) 394-405, http://dx. doi.org/10.1016/j.jallcom.2016.09.208.

[22] N.D. Stepanov, N.Y. Yurchenko, M.A. Tikhonovsky, G.A. Salishchev, Effect of carbon content and annealing on structure and hardness of the CoCrFeNiMn-based high entropy alloys, J. Alloy. Comp. 687 (2016) 59-71, http://dx.doi.org/10.1016/ j.jallcom.2016.06.103.

[23] N. Stepanov, M. Tikhonovsky, N. Yurchenko, D. Zyabkin, M. Klimova, S. Zherebtsov, A. Efimov, G. Salishchev, Effect of cryo-deformation on structure and properties of CoCrFeNiMn high-entropy alloy, Intermetallics 59 (2015) 8-17, http://dx.doi.org/10.1016/j.intermet.2014.12.004.

[24] Z. Wu, C.M. Parish, H. Bei, Nano-twin mediated plasticity in carbon-containing FeNiCoCrMn high entropy alloys, J. Alloy. Comp. 647 (2015) 815-822, http://dx. doi.org/10.1016/j.jallcom.2015.05.224.

[25] Z. Wu, Y. Gao, H. Bei, Thermal activation mechanisms and Labusch-type strengthening analysis for a family of high-entropy and equiatomic solid-solution alloys, Acta Mater. 120 (2016) 108-119, http://dx.doi.org/10.1016/j.actamat. 2016.08 .047$.
[26] Z. Li, C.C. Tasan, H. Springer, B. Gault, D. Raabe, Interstitial atoms enable joint twinning and transformation induced plasticity in strong and ductile high-entropy alloys, Sci. Rep. 7 (2017) 40704, http://dx.doi.org/10.1038/srep40704.

[27] Z. Li, K.G. Pradeep, Y. Deng, D. Raabe, C.C. Tasan, Metastable high-entropy dualphase alloys overcome the strength-ductility trade-off, Nature 534 (2016), http:/ dx.doi.org/10.1038/nature17981.

[28] N.D. Stepanov, D.G. Shaysultanov, M.A. Tikhonovsky, G.A. Salishchev, Tensile properties of the Cr-Fe-Ni-Mn non-equiatomic multicomponent alloys with different Cr contents, Mater. Des. 87 (2015) 60-65, http://dx.doi.org/10.1016/j.matdes. 2015.08.007.

[29] Z. Wang, I. Baker, Z. Cai, S. Chen, J.D. Poplawsky, W. Guo, The effect of interstitial carbon on the mechanical properties and dislocation substructure evolution in Fe40.4Ni11.3Mn34.8Al7.5Cr6 high entropy alloys, Acta Mater. 120 (2016), http:/ dx.doi.org/10.1016/j.actamat.2016.08.072.

[30] Z. Wang, I. Baker, W. Guo, J.D. Poplawsky, The effect of carbon on the microstructures, mechanical properties, and deformation mechanisms of thermo-mechanically treated Fe40.4Ni11.3Mn34.8Al7.5Cr6 high entropy alloys, Acta Mater. 126 (2017) 346-360, http://dx.doi.org/10.1016/j.actamat.2016.12.074.

[31] M.J. Yao, K.G. Pradeep, C.C. Tasan, D. Raabe, A novel, single phase, non-equiatomic FeMnNiCoCr high-entropy alloy with exceptional phase stability and tensile ductility, Scripta Mater. (2014) 72-73, http://dx.doi.org/10.1016/j.scriptamat.2013 09.030.

[32] Y. Deng, C.C. Tasan, K.G. Pradeep, H. Springer, A. Kostka, D. Raabe, Design of a twinning-induced plasticity high entropy alloy, Acta Mater. 94 (2015), http://dx. doi.org/10.1016/j.actamat.2015.04.014.

[33] B. Gwalani, V. Soni, M. Lee, S. Mantri, Y. Ren, R. Banerjee, Optimizing the coupled effects of Hall-Petch and precipitation strengthening in a $\mathrm{Al0} .3 \mathrm{CoCrFeNi}$ high entropy alloy, Mater. Des. 121 (2017) 254-260, http://dx.doi.org/10.1016/j.matdes. 2017.02.072.

[34] Z. Fu, W. Chen, H. Wen, D. Zhang, Z. Chen, B. Zheng, Y. Zhou, E.J. Lavernia, Microstructure and strengthening mechanisms in an FCC structured single-phase nanocrystalline Co25Ni25Fe25Al7.5Cu17.5 high-entropy alloy, Acta Mater. 107 (2016) 59-71, http://dx.doi.org/10.1016/j.actamat.2016.01.050.

[35] S.J. Sun, Y.Z. Tian, H.R. Lin, X.G. Dong, Y.H. Wang, Z.J. Zhang, Z.F. Zhang, Enhanced strength and ductility of bulk CoCrFeMnNi high entropy alloy having fully recrystallized ultrafine-grained structure, Mater. Des. 133 (2017) 122-127, http://dx.doi.org/10.1016/j.matdes.2017.07.054.

[36] J.Y. He, H. Wang, H.L. Huang, X.D. Xu, M.W. Chen, Y. Wu, X.J. Liu, T.G. Nieh, K. An, Z.P.P. Lu, A precipitation-hardened high-entropy alloy with outstanding tensile properties, Acta Mater. 102 (2016) 187-196, http://dx.doi.org/10.1016/j. actamat.2015.08.076.

[37] J.Y. He, H. Wang, Y. Wu, X.J. Liu, H.H. Mao, T.G. Nieh, Z.P. Lu, Precipitation behavior and its effects on tensile properties of FeCoNiCr high-entropy alloys, Intermetallics 79 (2016) 41-52, http://dx.doi.org/10.1016/j.intermet.2016.09. 005

[38] M. Klimova, N. Stepanov, D. Shaysultanov, R. Chernichenko, N. Yurchenko, V. Sanin, S. Zherebtsov, Microstructure and mechanical properties evolution of the $\mathrm{Al}$, C-containing CoCrFeNiMn-type high-entropy alloy during cold rolling, Materials (Basel) 11 (2017) 53, http://dx.doi.org/10.3390/ma11010053.

[39] Z. Wu, S.A. David, Z. Feng, H. Bei, Weldability of a high entropy CrMnFeCoNi alloy, Scripta Mater. 124 (2016) 81-85, http://dx.doi.org/10.1016/j.scriptamat.2016.06. 046.

[40] Z.G. Zhu, Y.F. Sun, M.H. Goh, F.L. Ng, Q.B. Nguyen, H. Fujii, S.M.L. Nai, J. Wei, C.H. Shek, Friction stir welding of a CoCrFeNiAl 0.3 high entropy alloy, Mater. Lett. 205 (2017) 142-144, http://dx doi.org/10.1016/j.matlet.2017.06.073.

[41] M.G. Jo, H.J. Kim, M. Kang, P.P. Madakashira, E.S. Park, J.Y. Suh, D.I. Kim, S.T. Hong, H.N. Han, Microstructure and mechanical properties of friction stir welded and laser welded high entropy alloy CrMnFeCoNi, Met. Mater. Int 24 (2018) 73-83, http://dx.doi.org/10.1007/s12540-017-7248-x.

[42] Z.G. Zhu, Y.F. Sun, F.L. Ng, M.H. Goh, P.K. Liaw, H. Fujii, Q.B. Nguyen, Y. Xu, C.H. Shek, S.M.L. Nai, J. Wei, Friction-stir welding of a ductile high entropy alloy: microstructural evolution and weld strength, Mater. Sci. Eng. A 711 (2018) 524-532, http://dx.doi.org/10.1016/J.MSEA.2017.11.058.

[43] Y. Cai, Y. Chen, Z. Luo, F. Gao, L. Li, Manufacturing of FeCoCrNiCux mediumentropy alloy coating using laser cladding technology, Mater. Des. 133 (2017) 91-108, http://dx.doi.org/10.1016/J.MATDES.2017.07.045.

[44] Q. Chao, T. Guo, T. Jarvis, X. Wu, P. Hodgson, D. Fabijanic, Direct laser deposition cladding of AlxCoCrFeNi high entropy alloys on a high-temperature stainless steel, Surf. Coating. Technol. 332 (2017) 440-451, http://dx.doi.org/10.1016/J. SURFCOAT.2017.09.072.

[45] F.Y. Shu, S. Liu, H.Y. Zhao, W.X. He, S.H. Sui, J. Zhang, P. He, B.S. Xu, Structure and high-temperature property of amorphous composite coating synthesized by laser cladding FeCrCoNiSiB high-entropy alloy powder, J. Alloy. Comp. 731 (2018) 662-666, http://dx.doi.org/10.1016/J.JALLCOM.2017.08.248.

[46] F.Y. Shu, L. Wu, H.Y. Zhao, S.H. Sui, L. Zhou, J. Zhang, W.X. He, P. He, B.S. Xu, Microstructure and high-temperature wear mechanism of laser cladded CoCrBFeNiSi high-entropy alloy amorphous coating, Mater. Lett. 211 (2018) 235-238, http://dx.doi.org/10.1016/J.MATLET.2017.09.056.

[47] V.N. Sanin, V.I. Yukhvid, D.M. Ikornikov, D.E. Andreev, N.V. Sachkova, M.I. Alymov, SHS metallurgy of high-entropy transition metal alloys, Dokl. Phys. Chem. 470 (2016) 145-149, http://dx.doi.org/10.1134/S001250161610002X.

[48] J.H.E. Jeffes, F.D. Richardson, J. Pearson, The heats of formation of manganous orthosilicate and manganous sulphide, Trans. Faraday Soc. 50 (1954) 364, http:// dx.doi.org/10.1039/tf9545000364.

[49] P.A. Thornton, The influence of nonmetallic inclusions on the mechanical properties of steel, J. Mater. Sci. 6 (1971) 347-356, http://dx.doi.org/10.1007/ 
BF02403103 T4-A_review_M4-Citavi.

[50] J. Maciejewski, The effects of sulfide inclusions on mechanical properties and failures of steel components, J. Fail. Anal. Prev. 15 (2015) 169-178, http://dx.doi. org/10.1007/s11668-015-9940-9.

[51] D.D. Gu, W. Meiners, K. Wissenbach, R. Poprawe, Laser additive manufacturing of metallic components: materials, processes and mechanisms, Int. Mater. Rev. 57 (2012) 133-164, http://dx.doi.org/10.1179/1743280411Y.0000000014.

[52] T. Gladman, Precipitation hardening in metals, Mater. Sci. Technol. 15 (1999) 30-36, http://dx doi.org/10.1179/026708399773002782.

[53] M.J. Jang, D.-H. Ahn, J. Moon, J.W. Bae, D. Yim, J.-W. Yeh, Y. Estrin, H.S. Kim, Constitutive modeling of deformation behavior of high-entropy alloys with facecentered cubic crystal structure, Mater. Res. Lett. 5 (2017) 350-356, http://dx.doi. org/10.1080/21663831.2017.1292325.
[54] P. Kürnsteiner, M.B. Wilms, A. Weisheit, P. Barriobero-Vila, E.A. Jägle, D. Raabe, Massive nanoprecipitation in an Fe-19Ni-xAl maraging steel triggered by the intrinsic heat treatment during laser metal deposition, Acta Mater. 129 (2017) 52-60, http://dx.doi.org/10.1016/j.actamat.2017.02.069.

[55] J.Y. He, W.H. Liu, H. Wang, Y. Wu, X.J. Liu, T.G. Nieh, Z.P. Lu, Effects of Al addition on structural evolution and tensile properties of the FeCoNiCrMn high-entropy alloy system, Acta Mater. 62 (2014) 105-113, http://dx.doi.org/10.1016/j.actamat. 2013.09.037.

[56] W.R.. Wang, W.L. Wang, S.C. Wang, Y.C. Tsai, C.H. Lai, J.W. Yeh, Effects of Al addition on the microstructure and mechanical property of AlxCoCrFeNi high-entropy alloys, Intermetallics 26 (2012) 44-51, http://dx.doi.org/10.1016/j.intermet. 2012.03.005 